\title{
Provincial Land Utilization Database Construction Analysis
}

\author{
Wenfeng LIAO, Shiwu XU \\ Land Resources Information Center of Guangdong, 468 East Huanshi Road, Guangzhou 510075, China \\ Faculty of Information Engineering, China University of Geosciences, Wuhan 430074
}

\begin{abstract}
According to the requirements of provincial land management operation, this paper introduced a method to build municipal land usage database on country level land usage database building. It realizes provincial land usage data updating, transfer and application management. This paper analyzed provincial land usage database construction requirements from data, software and hardware environment, database, etc. It also designed the mathematic base, land usage data feature, data dictionary and metadata. All the database construction process has been listed, including database configuration management, system optimization and security maintenance. at last, it presents some database applications which provides reference for the provincial land usage database construction.
\end{abstract}

Keywords: land usage; database

\section{省級土地利用資料庫建設分析}

\author{
廖文鋒，徐世武 \\ 廣東省國土資源資訊中心，廣州市環市東路 468 號，510075 \\ 中國地質大學(武漢)資訊工程學院，魯磨路 308 號，430074 \\ E-mail: gzlwf 302@126.com
}

\begin{abstract}
摘 要: 本文根據省級土地管理業務的需要, 利用縣（市）級土地利用資料庫建立省級土地利用資料庫，並實現 省級土地利用資料的更新、傳送及應用管理。從資料、軟硬體環境和資料庫等方面分析省級土地利用資料庫建設 的需求與準備，對資料庫的數學基礎、土地利用資料要素、資料字典及元資料等進行設計，列出資料庫的建庫流 程, 分析了資料庫配置管理、系統性能優化和安全等的管理維護, 最後還講述了資料庫的一些應用, 為省級土地 利用資料庫的建設提供一些參考。
\end{abstract}

關鍵字：土地利用；資料庫

\section{1. 前 言}

土地是人類賴以生存的基礎，為了更好地保護 和合理利用土地，充分發揮土地的經濟和社會效 益，準確把握土地利用現狀及其動態變化趨勢，提 高土地的合理規劃、高效管理、科學決策以及為社 會提供基礎性、公益性資訊服務的能力與水準，必 須加強土地管理的資訊化建設，土地利用資料是土 地管理的基礎資料。

目前省級土地管理業務主要有: 建設用地審批地 類審核、耕地開發複墾整理專案立項地類審核、補充
耕地驗收確認地類審核以及土地利用資料統計等。通 過利用全省各市、縣建成的縣（市）級土地利用資料 庫資料，進行資料格式轉換、投影轉換、資料入庫 等，建立起省級土地利用資料庫，並實現每年土地 變更調查後的土地利用資料更新，即時進行資料的網 路傳送和管理，為省級的各項土地管理業務提供強有 力的保障和服務, 成為省級國土資源資訊化的重要組 成部分。 


\section{2. 資料庫建設的需求與準備}

省級土地利用資料庫建設的需求與準備主要有如 下內容:

1)數據。來源是全省各縣 (市) 的土地利用資料 庫資料。通過制定《省級土地利用資料庫匯交標準》, 明確規定全省各個縣(市)匯交的土地利用資料內容、 範圍、形式[1], 使不同比例尺、不同軟體平臺的縣(市) 級土地利用資料庫資料在遵循《匯交標準》的前提下 統一匯交格式, 經過檢查、接邊、組織和整合後導入 省級土地利用資料庫[2]; 首次匯交全部資料, 以後每 年龨交增量資料。

2)軟硬體環境。硬體環境包括場地、資料庫伺服 器、微機設備、網路服務器設備、輸入輸出設備等; 軟體環境包括資料庫伺服器作業系統、微機作業系 統、Web 服務、資料庫系統、GIS 平臺、軟體發展工 具、系統的網路結構等。

3)資料庫的基本管理功能。包括初始資料入庫、 更新資料入庫、資料出庫、資料統計匯總、地圖流覽、 查詢、資料裁切、柵格底圖與向量層疊加顯示等[2]。

4)歷史資料的歸檔、備份和管理。

5)網路要素服務。包括服務能力的描述、要素類 型描述、要素獲取等。

6)資料共用功能。包括線上地圖顯示、查詢功能、 資料提取下載等。

7)產品品質。包括資料庫的正確性、健壯性、性 能效率、易用性等。

\section{3. 資料庫設計}

省級土地利用資料庫建設對資料庫主要進行如下
設計：

1)資料庫的數學基礎。包括：坐標系（採用 1980 西安坐標系）; 高程基準（採用 1985 國家高程基準） [2]; 向量資料 (一般採用經緯度建庫, 在縣 (市) 級 土地利用資料匯交入庫時, 由於縣（市）級數據採用 的是高斯-克呂格投影, 因此在入庫時需要進行投影變 換）; 柵格資料（採用高斯-克吕格投影，座標按 $3^{\circ}$ 帶分帶建庫）; 省級庫中資料跨比例尺存儲, 各個縣 市提交的不同比例尺資料按照不同比例尺的分幅或分 區域標準入庫，邏輯上無縫建庫。

2)資料庫的土地利用資料 ER 圖.如圖 1 所示。

3)資料庫的土地利用要素表。土地利用要素的屬 性項內容參照文獻[1]及《省級土地利用資料庫匯交標 準》制定，並通過各個表具體進行描述。如表 1 所示。

4)資料庫的資料字典表。土地利用資料庫表中某 些欄位的內容必須填寫規定的值, 將這些欄位的內容 以代碼表形式組織、管理, 作為資料庫的資料字典。 如表 2 所示。

5)資料庫的土地利用現狀與歷史。在建庫中, 將 各類土地利用要素的現狀和歷史資料統一存放在各個 要素表中, 表中增加“起始日期”及“終止日期”項以反 映要素的生命週期。“起始日期”記錄了要素產生的時 間, 而“終止日期”則記錄了要素變更消亡的時間, 對 於現狀的要素，其“終止日期”項為空。對表進行查詢 時通過設置在“起始日期”和“終止日期”上的條件，可 以體現出任意歷史時刻的土地利用狀況, 甚至可以反 映出給定的某個空間範圍、一定時間內土地利用的演 化過程。
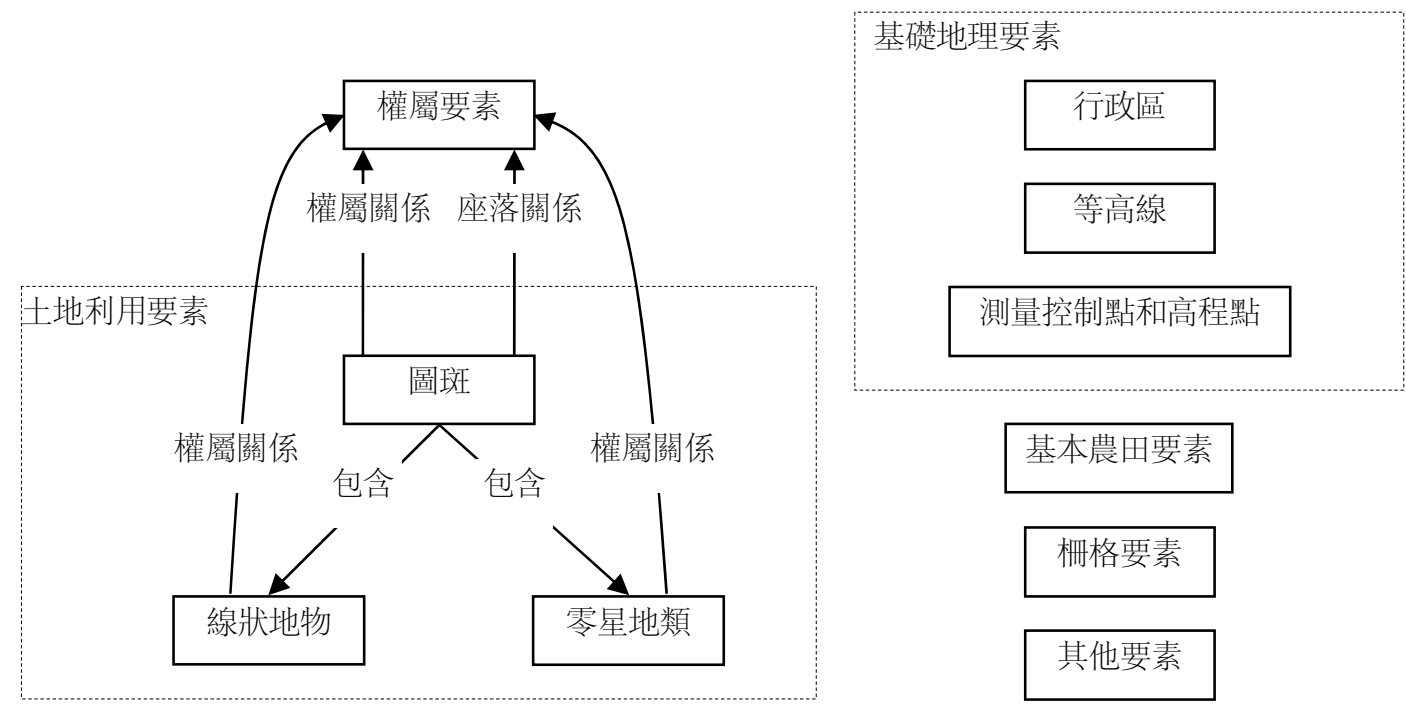

圖 1. 資料庫的土地利用資料 $\mathrm{ER}$ 圖 
表 1. 資料庫的土地利用要素表

\begin{tabular}{clc}
\hline 表 名 & \multicolumn{1}{c}{ 說 } & 明 \\
\hline XZQY & 行政區表 & 註 \\
XZJX & 行政界線表 & 線 \\
DGXB & 等高線表 & 線 \\
KZGC & 測量控制點和高程點表 & 點 \\
QSQY & 權屬區表 & 面 \\
QSJX & 權屬界線表 & 線 \\
QSGD & 權屬界線拐點表 & 點 \\
DLTB & 地類圖斑表 & 面 \\
XZDW & 線狀地物表 & 線 \\
LXDL & 零星地類表 & 點 \\
DLJX & 地類界線表 & 線 \\
JBNT & 基本農田表 & 面 \\
ZJFH & 注記表 & 注記 \\
QTYS & 其他要素表 & Geometry \\
\hline
\end{tabular}

表 2. 資料庫的資料字典表

\begin{tabular}{cl}
\hline 表 名 & \multicolumn{1}{c}{ 說 } \\
\hline YSDM & 明要素代碼表 \\
DLDM & 地類代碼表 \\
JXXZ & 界線性質代碼表 \\
QSXZ & 權屬性質代碼表 \\
PDDM & 耕地坡度級代碼表 \\
XQDM & 行政權屬代碼表 \\
TFXX & 圖幅信息表 \\
\hline
\end{tabular}

6)資料庫的元資料。通過管理、更新、維護元資料來 發佈空間資料集資訊。元資料管理的空間資料集資訊由標 識資訊、資料品質資訊、參照系統資訊、內容資訊、分 發資訊、以及聯繫資訊等構成[3,4]。

\section{4. 資料庫建庫流程}

資料庫建庫流程如圖 2 所示。

\section{5. 資料庫的管理維護}

省級土地利用資料庫的管理維護主要有如下內容:

1)資料庫配置管理。系統採用多線索伺服器體系 結構, 多線索伺服器配置的優點是降低系統開銷, 增 加用戶個數。

2)資料庫系統性能優化。由於資料庫系統運行條 件的改變，必須持續不斷地在資料庫系統上執行優化 操作, 資料庫系統性能優化主要集中在幾個方面: (1) 客戶機優化: 對客戶機的軟硬體配置進行優化可以有 效改善系統的運行效率; (2) 網路優化: 網路性能對 於系統運行有著極大的影響, 需要認真的加以監控和 及時的調整;（3）SQL 語言優化: 資料庫的反應速 度經常就體現在一個優化演算法上, 不同的查詢策略 和查詢步驟可使伺服器的反應不同，因此採用適當的 查詢策略可使系統性能大大提高; (4) 空間資料引擎 配置優化。

3)資料庫系統安全。包括資料存儲安全及運行安 全兩個方面，資料存儲安全是指資料庫的自動備份及 恢復；資料庫系統的運行安全則通過建立完善的系统

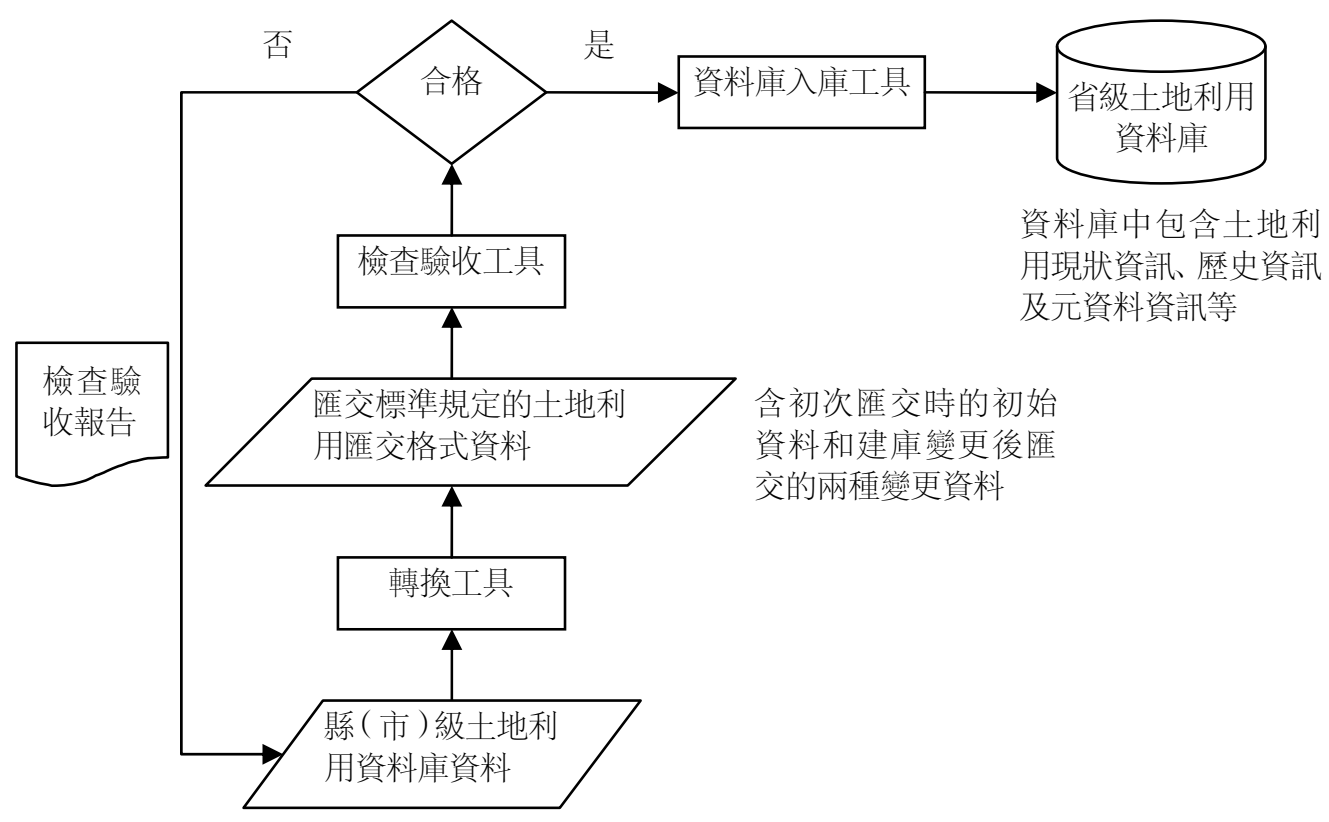

圖 2. 資料庫建庫流程 
訪問機制來解決，包括資料密級劃分、用戶許可權管 理、安全控制流程、系統日誌機制等。

\section{6. 資料庫的應用}

對省級士地利用資料庫進行開發，可實現如下應用:

1)省級土地利用資料的匯總, 輸出並上報匯總資 料。 匯總。

2)省級土地利用資料庫的變更，並進行變更資料

3)進行建設用地審批地類審核、耕地開發複墾整 理專案立項地類審核 補充耕地驗收確認地類審核等。

4)通過網路為省政府、土地主管部門、各單位和 個人提供服務等。

\section{參考文獻 (References)}

［1］中華人民共和國國土資源部．TD/T 1016-2007 土地利 用資料庫標準[s]. 北京：中華人民共和國國土資源部, 2007.

［2］中華人民共和國國土資源部．TD/T 1014-2007 第二次 全國土地調查技術規程[s]．北京：中華人民共和國國 土資源部, 2007.

[3] 中華人民共和國國土資源部. TD/T 1016-2003 國土資 源資訊核心元資料標準[s]. 北京:中華人民共和國國土 資源部, 2007.

[4] 國家測繪局. CH/T 1007-2001 基礎地理資訊數位產品 元資料[s]. 北京: 測繪出版社, 2001. 